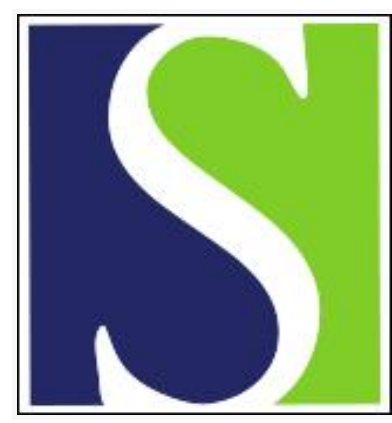

Scand J Work Environ Health 2014;40(1):47-56

https://doi.org/10.5271/sjweh.3383

Published online: 17 Sep 2013, Issue date: 01 Jan 2014

Effect of the Danish return-to-work program on long-term sickness absence: results from a randomized controlled trial in three municipalities

by Poulsen OM, Aust B, Bjorner JB, Rugulies R, Hansen JV, Tverborgvik T, Winzor G, Mortensen OS, Helverskov T, Ørbæk P, Nielsen MBD

This is the largest RCT ever conducted on effects of a multiple component return-to-work intervention (coordinated, tailored, and multidisciplinary). The effects of the intervention on duration of sickness absence were remarkably different between the three municipalities examined indicating that contextual factors are of major importance for success or failure of this complex intervention.

Affiliation: National Research Centre for the Working Environment, Lersø Parkalle 105, DK-2100 Copenhagen, Denmark. omp@nrcwe.dk

Refers to the following text of the Journal: 2012;38(2):120-133

The following articles refer to this text: 2015;41(3):219-221;

2015;41(6):529-541; 2016;42(4):273-279

Key terms: coordinated case management; Denmark; effect evaluation; intervention; long-term sickness absence; multidisciplinary; randomized controlled trial; return to work; return-to-work program; sickness absence; work resumption

This article in PubMed: www.ncbi.nlm.nih.gov/pubmed/24045856

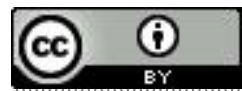




\title{
Effect of the Danish return-to-work program on long-term sickness absence: results from a randomized controlled trial in three municipalities
}

\author{
by Otto M Poulsen, DrVetSc, ${ }^{1}$ Birgit Aust, PhD, ${ }^{1}$ Jakob Bue Bjorner, PhD, 1, 2, 3 Reiner Rugulies, PhD, 1,2,4 \\ Jorgen V Hansen, PhD ${ }^{1}$ Torill Tverborgvik, PhD, ${ }^{1,5}$ Glen Winzor, MSc, ${ }^{1}$ Ole S Mortensen, PhD, ${ }^{1,6}$ Trine \\ Helverskov, MSc, ${ }^{1}$ Palle Ørbæk, DrMedSc, ${ }^{1}$ Maj Britt D Nielsen, $P h D{ }^{1}$
}

\begin{abstract}
Poulsen OM, Aust B, Bjorner JB, Rugulies R, Hansen JV, Tverborgvik T, Winzor G, Mortensen OS, Helverskov T, Ørbæk P, Nielsen MBD. Effect of the Danish return-to-work program on long-term sickness absence: results from a randomized controlled trial in three municipalities. Scand J Work Environ Health. 2014;40(1):47-56. doi:10.5271/ sjweh.3383
\end{abstract}

Objectives The aim of this study was to evaluate the effect of the Danish return-to-work (RTW) program on long-term sickness absence in a randomized controlled trial in three municipalities.

Methods The intervention group comprised 1948 participants while the control group comprised 1157 participants receiving ordinary sickness benefit management (OSM). Study participants were working-age adults receiving long-term ( $\geq 8$ weeks or more) benefits, included regardless of reason for sickness absence or employment status. Each beneficiary was followed-up for a maximum period of 52 weeks. Cox proportional hazards model was used to estimate hazard ratios (HR) for return to work (RTW) with $95 \%$ confidence intervals $(95 \% \mathrm{CI})$.

Results The intervention effect differed significantly between the municipalities $(\mathrm{P}=0.00005)$. In one municipality (M2) the intervention resulted in a statistically significant increased rate of recovery from long-term sickness absence (HR 1.51, 95\% CI 1.31-1.74). In the other two municipalities, the intervention did not show a statistically significant effect $\left(\mathrm{HR}_{\mathrm{M} 1} 1.12,95 \%\right.$ CI $0.97-1.29$, and $\mathrm{HR}_{\mathrm{M} 3} 0.80,95 \%$ CI $0.63-1.03$, respectively). Adjustment for a series of possible confounders only marginally altered the estimated HR.

Conclusion The effect of the intervention differed substantially between the three municipalities, indicating that that contextual factors are of major importance for success or failure of this complex intervention.

Key terms coordinated case management; Denmark; effect evaluation; intervention; multidisciplinary; RTW; work resumption.

In 2008, the annual level of sickness absence in Denmark corresponded to approximately $5 \%$ of the workforce, and reimbursement costs per year were estimated to be around $€ 5$ billion (approximately $€ 1350$ per capita age 18-64 years) not including treatment costs or loss of productivity (1). Promoting labor market participation is essential for Denmark and other European countries facing a decline in the proportion of people of working age due to an aging workforce (2). To reduce sickness absence and improve labor market participation, the Danish Government launched an action plan in 2008 encompassing 39 initiatives including the Danish returnto-work (RTW) program. The Danish National Research Centre for the Working Environment (NRCWE) was appointed to develop the program in accordance with the action plan, existing sickness management legislation, and previous experiences from national and international intervention studies.

1 National Research Centre for the Working Environment, Copenhagen, Denmark.

2 Department of Public Health, University of Copenhagen, Copenhagen, Denmark.

3 QualityMetric, Lincoln, Rhode Island, USA.

4 Department of Psychology, University of Copenhagen, Copenhagen, Denmark.

5 National Institute of Occupational Health, Oslo, Norway.

6 Department of Occupational and Environmental Medicine, Bispebjerg Hospital, Copenhagen, Denmark.

Correspondence to: Otto Melchior Poulsen, DrVetSc, National Research Centre for the Working Environment, Lersø Parkalle 105, DK-2100 Copenhagen, Denmark. [E-mail: omp@nrcwe.dk] 
Most RTW interventions focus on specific target groups, mostly sick-listed individuals with musculoskeletal health problems (3-10), whereas RTW interventions addressing mental health problems are scarce $(11,12)$. A recent systematic review of the effectiveness of RTW interventions for persons sick-listed due to musculoskeletal problems concluded that most interventions appeared beneficial. However, the effects were rather small and publication bias may have occurred (5). Another review concluded that most intervention studies were small and of limited quality (13). In addition, most previous RTWintervention projects have focused on a single intervention element [ie, the effects of RTW coordinators (14), multidisciplinary teams $(9,10,13)$, or work accommodation by healthcare providers (13)].

Contrary to these previous studies, the goal of the Danish RTW program was to encompass a broad group of sick-listed persons, including sick-listed beneficiaries with both somatic and mental health problems and with all types of employment status (employed, self-employed, temporary employed, or unemployed). In addition, the program is based on a combination of a coordinated, tailored and multidisciplinary (CTM) approach, including designated RTW coordinators and multidisciplinary teams, and work accommodation by healthcare providers was used when appropriate. The basic assumption of the Danish program was that the concerted action of both the RTW coordinator and team ensured better clarification of the barriers and resources for RTW and a faster initiation of RTW activities, which were better tailored to meet the specific needs of each sick-listed beneficiary.

The Danish RTW program comprised a stratified cluster-controlled study in 21 municipalities and a randomized controlled trial (RCT) in 3 municipalities. The effect evaluation of the RCT aimed to test the following four hypothesis regarding effects of the CTM intervention: participants in the intervention (i) have a shorter duration of full-time sickness absence, (ii) have a longer time off sick before recurrent long-term sickness absence (have a more sustainable RTW), (iii) are faster in achieving a full RTW, and (iv) report a more positive development in self-rated general health, mental and physical health, workability, pain, and sleep.

This present article presents the results related to the first hypothesis. In addition, two supplementary hypotheses related to time-dependency of the effect were tested: (i) the effect of the CTM intervention would improve with time after onset of the project (learning processes could be potential explanations for effect increasing with time); and (ii) the CTM intervention would be more beneficial in the more complex sickness absence cases, defined as long-lasting cases. Consequently the effect of the CTM intervention would be more pronounced late in the long-lasting sickness absence cases.

\section{Methods}

Full details of the intervention and evaluation design of the RTW program have previously been published (15).

\section{Study design}

In the present study, a RCT design with individual randomization was used in 3 of the 21 municipalities (hereafter denominated as M1, M2, and M3) participating in the Danish RTW program. These 3 municipalities were eligible for RCT because they met the following criteria: (i) they had separated sub-units of their sickness benefit management offices serving the same population allowing for randomization at the individual level of sick-listed beneficiaries to an intervention or control office; (ii) the sickness benefit office sub-units were geographically separated, thereby reducing the risk of intervention spill-over between the CTM intervention and ordinary sickness benefit management (OSM); and (iii) the number of sick-listed beneficiaries eligible for the study was sufficiently high to generate a large intervention and comparable control group.

The evaluation of the RTW program consisted of an effect and process evaluation; a research group at the NRCWE designed and conducted both evaluations.

\section{Selection of municipalities}

In 2009, the Danish National Prevention Fund invited all 98 Danish municipalities to apply for participation in the program. The applications had to include a plan for the implementation of the program. A total of 44 municipalities applied for participation, but 10 were excluded since they already had ongoing interventions with elements resembling the RTW program. Among the remaining 34 municipalities, 21 were selected to participate in the program, and of these only 3 municipalities (M1, M2, and M3) were eligible for the RCT design (for further details of the selection process see 15).

\section{Study population}

According to Danish law, the employer pays sickness benefits during the first 3 weeks after which the municipality takes over payment for a maximum of 52 weeks, within a period of 78 weeks. Hence, the general rule is that sickness benefits from the employer and municipality can be obtained for $\leq 55$ weeks in total. If sickness benefits from the municipality have been paid within the last 78 weeks, the period for obtaining sickness absence benefits for the current sickness absence spell is reduced accordingly (on 1 January 2012, the employer period was increased to 30 days). The municipalities are 
obliged by law to conduct an assessment of every sicklisted beneficiary by the end of the $8^{\text {th }}$ week of sickness absence. At this assessment, beneficiaries are assigned to one of three categories: (i) category $1=$ likely to return to work within three months; (ii) category $2=$ unlikely to return to work within three months, but able to participate in RTW activities like gradually returning to work; and (iii) category $3=$ unlikely to return to work within three months and unable to participate in RTW activities. All category 2 beneficiaries were included in the trial. In each of the three RCT municipalities, a sickness benefit officer or administrative employee administered the randomization using a web-survey program, which automatically allocated all eligible beneficiaries to a control or intervention sickness benefit unit. The result of the randomization was instantly available for the sickness benefit officer and registered in a central database at NRWCE. Each municipality had a fixed budget from the Danish National Prevention Fund dictating an expected total number of beneficiaries to receive the CTM intervention. Consequently, for each municipality, NRCWE regularly adjusted the allocation ratio in the web-survey program to ensure that the required total number of beneficiaries in the intervention was reached. From 1 April 2010 to 31 December 2011, a total of 5189 sick-listed beneficiaries of working age were classified as Category 2.

The intention-to-treat approach was in principle selected for the statistical analyses. Since the intervention was in accordance with the existing Danish sickness management legislation, the beneficiaries could not refuse to receive the intervention, but they could refrain from completing the questionnaire or taking part in interviews evaluating the intervention. The following study criteria were decided prior to data analysis (see figure 1). If a beneficiary entered the study more than once, only the first sickness absence spell was used in the analyses (172 cases excluded). The first three months of the intervention (April-June 2010) were defined as an introductory period during which the number of cases handled by the RTW coordinator and team gradually increased, allowing them to become familiar with the interdisciplinary collaboration, the specific tools, and new methods of the CTM intervention. Since it was anticipated that case management during the first three month would differ profoundly from the subsequent case management in routine operation of the CTM intervention, cases from the first three months were excluded from the effect analyses (1113 cases). The web-survey program for automatical randomization was gradually implemented in the municipalities during the introductory period, and data on randomization was missing for approximately one third of the beneficiaries included during the introduction period (416 cases). As assumed, the majority of study participants were recruited at the moment of their classification into categories 1, 2, or 3 after being sick-listed for 8 weeks. However, a small number of beneficiaries made first contact with the municipal sickness benefit offices at a later stage. As the project focused on initiating the intervention at an earlier stage, beneficiaries who were sick-listed for $>120$ days before contacting the sickness benefit office were excluded ( 65 cases). One beneficiary had missing data on whether she had been allocated to the CTM or OSM. Furthermore, 477 persons had inconsistent data on the actual day of reporting sick when comparing register data with the administrative records of the municipal sickness benefit office. Beneficiaries on maternity leave or living abroad the week before the first day of sickness absence and those who received disability-related benefits six months prior to their sickness absence spell were excluded (239 cases). Finally 17 beneficiaries who had exceeded their compensation limit at the time of inclusion in the trial were also excluded. The total study population for the primary statistical analysis comprised 3105 beneficiaries: 1157 receiving OSM and 1948 receiving the CTM intervention.

\section{Data for effect evaluation}

Data registered at the sickness benefit office. From the administrative forms completed by the sick-listed beneficiaries, information was retrieved on reason for sickness absence and date of first day of sickness absence.

Data from national registries. The Danish Register for Evaluation of Marginalization (the so-called "DREAM" register) contains information on all social transfer payments on a weekly basis, including previous sickness and unemployment benefits (16). The main outcome "week of recovery from sickness absence" was defined by first week of no sickness absence benefit. At the time of data analysis, the DREAM register included social transfer payments until 29 April 2012. Register-based data on age, gender, education, employment status at first day of sickness absence, purchase of prescribed medicine, contact with own general practitioner, and history of hospital admission were obtained from Statistics Denmark.

\section{Content of the CTM intervention}

The CTM intervention consisted of three core elements: (i) establishment of multidisciplinary RTW teams within the municipalities, (ii) introduction of standardized workability assessments and multidisciplinary sickness absence management procedures, and (iii) a 3-week training course for all multidisciplinary RTW teams prior to the program. 


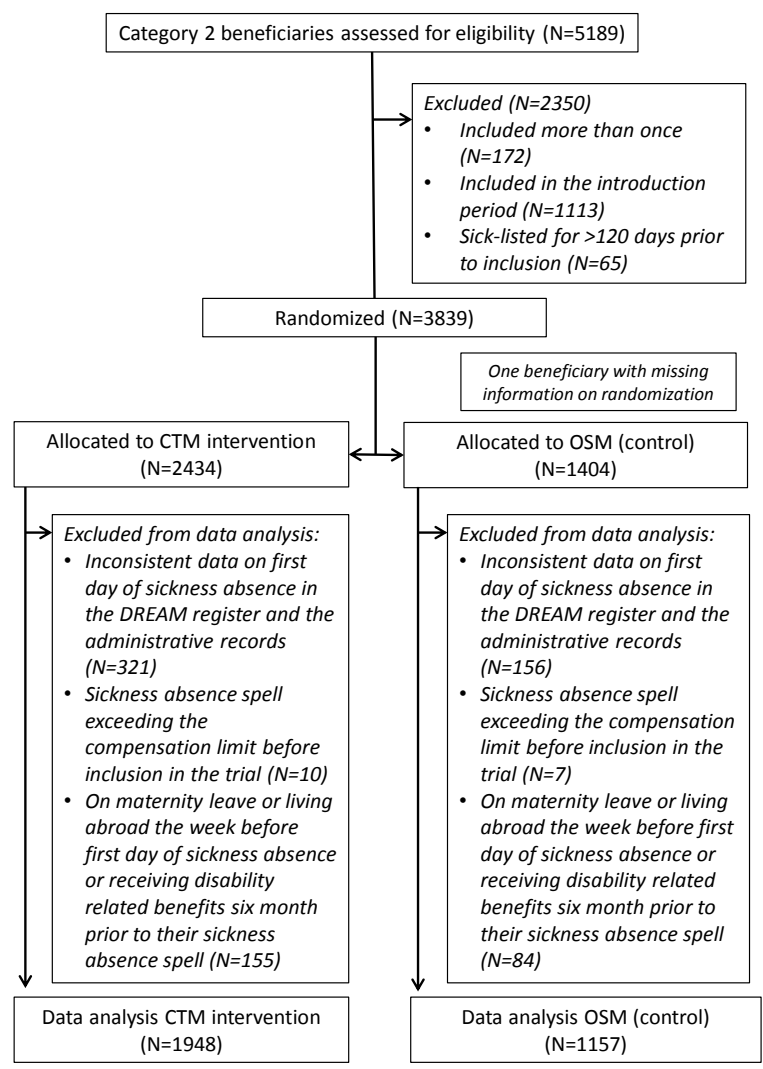

Figure 1. Flow chart on exclusion of participants. [CTM=coordinated, tailored and multidisciplinary; DREAM=Danish Register for Evaluation of Marginalization; OSM=ordinary sickness benefit management.]

\section{Establishment of multidisciplinary RTW teams}

Depending on their population size, the municipalities in the Danish RTW program had to establish an appropriate number of multidisciplinary RTW teams. Each team consisted of two RTW coordinators (municipal sickness benefit officers), a psychologist, physical therapist, psychiatrist, and physician (specialist in occupational, social, or general medicine). The NRCWE regulated the intake of participants through the randomization procedures ensuring an annual intake of 170 beneficiaries per RTW team. Therefore the RTW teams had an upper limit to their case load, which was not the case in OSM. The RTW coordinator was responsible for conducting regular follow-up of all sick-listed participants in accordance with the law (at least every fourth week) and coordinating RTW initiatives with the other members of the multidisciplinary RTW team. The introduction of the multidisciplinary RTW teams enabled closer cooperation between municipal officers and health professionals compared to OSM.
Introduction of a standardized RTW assessment tool and multidisciplinary sickness-absence management procedures

A standardized RTW assessment tool based on a biopsychosocial understanding of health and disability was developed. The RTW assessment tool should enable the RTW coordinators to conduct a systematic assessment identifying the needs of each sick-listed beneficiary. The assessment tool covered barriers and resources for RTW related to physical and mental health, work, and occupational experiences. The tool had to be used in the first consultation between the RTW coordinator and the sick-listed beneficiary thereby providing an early, detailed basis for future RTW activities. Using this tool, RTW coordinators were expected to be able to manage about half of all cases without discussing them at the weekly multidisciplinary team meetings. Nevertheless, the RTW coordinators could always contact the other members of the RTW team to clarify health-related questions. In more complex cases, the RTW coordinators could refer beneficiaries to the other team members for further workability assessment, after which these cases were discussed with all RTW team members in the weekly mandatory multidisciplinary team meetings to qualify assessments and decisions. The possibility of direct and frequent exchange between all members of the multidisciplinary team was one of the key ways in which CTM intervention substantially differed from OSM. While ordinary sickness benefit officers could request further information from other health professionals, they did not have the possibility to discuss a complex case with several experts at the same time. Additionally, OSM-requested assessments from one or several experts took time, and the experts' feedback did not take each other's viewpoints into account.

Just as in OSM, and in accordance with the law, the RTW coordinators were responsible for developing an individual RTW plan and conducting the mandatory consultations with all beneficiaries. Additionally, in the CTM intervention, the RTW coordinators were also responsible for coordinating the different RTW activities with special emphasis on close collaboration between the RTW team members and external stakeholders, such as the employer. RTW activities could, as in OSM, include meetings with workplaces, work modifications, workability training, gradual RTW, education/training (eg, psychoeducation, ergonomics training, physical exercises, and stress and pain management). In the CTM intervention, the RTW team's health professionals could participate in the activities (ie, meetings with workplaces or education/training). It was anticipated that having the same health professionals participate in both the assessment and follow-up activities would improve coordination and continuity 
compared to OSM. To further support a more standardized sickness management procedure and good information flow between all RTW team members, several other tools were developed for the program. These included guidelines for the meetings between the sick-listed beneficiaries and the other RTW team members (psychologists, physiotherapists, physicians, and psychiatrists) and a number of templates for information exchange.

\section{Training course for RTW team members}

Before the onset of the Danish program, all RTW coordinators, psychologists, and physiotherapists participated in a 3-week training course, with physicians and psychiatrists participating in selected parts. The course consisted of a mixture of theoretical lectures, practical casework, role plays, and exercises. The aim of the course was to ensure that all RTW teams had the necessary knowledge and skills to deliver the CTM intervention. The course focused on topics such as a biopsychosocial understanding of health, the central role of the RTW coordinator (eg, coordinating the input from the other team members and advancing the RTW process) and multidisciplinary teamwork (eg, using and respecting each other's expert knowledge and contributing to a joint RTW plan). Another topic was the cooperation with workplaces and other stakeholders (eg, the beneficiaries' physician). Following the training course, two course managers from the research group at the NRCWE visited all RTW teams on a regular basis (approximately every third month) throughout the program period to facilitate the implementation process.

\section{Statistical analysis}

Within each of the three municipalities, the Cox proportional hazards model was used to estimate the effect of the intervention on rates of recovery from sickness absence. Effects are presented as hazard ratios (HR) with $95 \%$ confidence intervals $(95 \% \mathrm{CI})$. In addition, average recovery rates for CTM and OSM were calculated for each of the three municipalities. The week of reporting sick was used as the origin of the timescale from which recovery from sickness absence was defined to be the first week where no sickness absence benefit was given. We used delayed entry (left truncation) at week of randomization to include only beneficiaries receiving sickness absence benefits at randomization. The beneficiaries were censored at the start of the week where they were no longer entitled to sickness benefit within the standard limits (a maximum of 52 weeks within a period of 78 weeks) given by law. Beneficiaries who retired, died, emigrated, or (temporarily) left the labor market due to maternity leave were censored at their last week of receiving sickness benefits. Beneficiaries still on sick leave by 29 April 2012 were also censored at this time point.

We originally planned to estimate the overall effect of the CTM intervention in the RCT, assuming an identical effect of the intervention in the three municipalities (15). However, the statistical analyses revealed different effects, and, consequently, we decided not to present estimates on an overall effect based on this assumption. Hence, the effect of the CTM intervention is reported for each of the three municipalities separately.

\section{Robustness analysis}

Even though it may seem reasonable to consider the first three months of the intervention an introductory period, it may be equally reasonable to argue that such a period is a natural part of every intervention and that inclusion of the beneficiaries in the introductory period may result in more trustworthy estimates of the overall effects of the intervention. Hence, beneficiaries who were randomized to the CTM intervention or OSM during the introductory period were included in the robustness analysis $(N=697)$. Similarly, 477 beneficiaries were excluded because they had inconsistent data on sickness absence benefits in relation to the recorded day of entry in the population. However, exclusion was clearly warranted only in the case of 90 beneficiaries as it was not possible to establish whether they were actually sick-listed. For the remaining 387 beneficiaries, uncertainty existed on when sick-listing occurred, but since it was possible to assign a date of sick-listing, they were included in the robustness analysis. The robustness analyses (ie, closer to an ideal intention-to-treat approach) comprised 4189 beneficiaries in total.

Since the study design is a RCT, we expected randomization to ensure that the HR were not biased by confounding. Hence, we considered the unadjusted HR to be the main results. However, adjusted HR were estimated as part of the robustness analyses. The calculated HR were adjusted for the following potential confounders: reason for sickness absence (primarily somatic versus mental health problems), gender, age, educational level, history of long-term $(\geq 3$ weeks) sickness absence (any sickness benefits within the last 78 weeks, yes/no), history of unemployment (any unemployment benefits within the last 78 weeks, yes/no), employment status at inclusion in the study (employed/unemployed), number of contacts with own practitioner $(0-6, \geq 7$ in the calendar year prior to entering the study), history of hospital admission (any hospital admissions or contacts with psychiatric treatment in the year prior to entering the study, yes/no), and purchase of prescribed medicine (any purchase in the year prior to entering the study, yes/no). 


\section{Supplementary analysis}

To analyze whether the effect of the CTM intervention was dependent on time-after-project initiation, the entire project period (excluding the 3-month introductory period) was divided into four time intervals: (i) 1 July 2010-2 January 2011, (ii) 3 January 2011-3 July 2011, (iii) 4 July 2011-1 January 2012, and (iv) 2 January 2012-29 April 2012. Similarly, in order to analyze if the effect of the intervention was dependent on the duration of sickness absence since the first day of sickness absence, the period was divided into four periods within which recovery from sickness absence occurred: (i) before week 17, (ii) week 17-29, (iii) week 30-42, and (iv) 43-55 of sickness absence. In both cases, the effect of the intervention was estimated for each interval and each of the three municipalities by the use of time-varying covariates defined by the interval endpoints. Timedependent effects on one time scale were not adjusted for possible time-dependent effects on the other.

The PHREG procedure of SAS version 9.2 (SAS Institute, Cary, NC, USA) was used for the analyses.

\section{Results}

Only Category 2 beneficiaries were eligible for the RTW program. The proportion of these beneficiaries in M1, M2, and M3 was 50\%, 26\%, 24\%, respectively. Furthermore, the proportion of beneficiaries randomized to CTM and OSM in M1, M2, and M3 before eight weeks of sickness absence was $88 \%, 33 \%$, and $91 \%$, respectively. After ten weeks of sickness absence, the proportion of beneficiaries who had been randomized was $94 \%, 79 \%$, and $94 \%$, respectively.

Background characteristics of beneficiaries in the control and intervention groups in the three municipalities are presented in table 1 . The higher number of beneficiaries receiving CTM as compared to OSM reflected that NRCWE controlled the allocation ratio to ensure the number of beneficiaries randomized to CTM was equal to the number required in the funding budget of each municipality. The percentage allocated to CTM was $60 \%$ in $\mathrm{M} 1,60 \%$ in $\mathrm{M} 2$ and $75 \%$ in M3. M2 differed from M1 and M3 in having a higher fraction of beneficiaries who (i) were sick-listed from unemployment and (ii) had a history of long-term sickness absence. M3 differed from M1 and M2 in having a larger fraction of beneficiaries with mental health problems and a lower fraction with a basic level of education. Within each municipality, the only statistically significant difference between CTM and OSM was observed in M2 where the fraction of women receiving CTM was significantly higher than those receiving OSM. Considering that 30 parameters were compared (10 per municipality) it was not surprising that one would emerge as statistically significant. However, we have no explanation for the large gender difference between CTM and OSM in M2.

Table 2 presents the estimated HR in each of the three municipalities in the RCT. In M2, the intervention resulted in a significant increase in recovery from longterm sickness absence $\left(\mathrm{HR}_{\mathrm{M} 2} 1.51,95 \%\right.$ CI 1.31-1.74) whereas in the two other municipalities, no significant effects of the intervention were found $\left(\mathrm{HR}_{\mathrm{M} 1} 1.12\right.$, 95\% CI 0.97-1.29, $\mathrm{HR}_{\mathrm{M} 3} 0.80,95 \%$ CI $0.63-1.03$ ). Confounder adjustment altered the estimated HR only marginally. A robustness analysis including the 697 beneficiaries randomized to the study population during the 3-month introductory period and 387 beneficiaries who were originally excluded due to uncertainty on the actual date of sick-listing yielded similar results as the main analysis (table 2).

Table 3 presents the supplementary analyses of the time-dependent effects of the CTM intervention in all three municipalities. In M2, differences in effects between time intervals approached statistical significance $(\mathrm{P}=0.07)$ with the smallest estimated effect in the first interval (1 July 2010-2 January 2011). No time dependence was observed in $\mathrm{M} 1$ or $\mathrm{M} 3$.

Table 4 presents the estimated effects depending on duration of sickness absence since first week of sickness absence. The intervention effects were different only in $\mathrm{M} 1(\mathrm{P}=0.02)$ in the four 13-week long intervals with estimated effect highest at the end of long sickness absence spells.

\section{Discussion}

To our knowledge, this is the largest RCT ever conducted on the effects of a multiple component RTW-intervention based on a CTM approach. The effects of the intervention on duration of sickness absence were remarkably different between the three municipalities. Originally we intended to estimate the overall effect of the CTM intervention assuming identical effects in all municipalities (15). However, a test of interaction between the intervention and municipality showed that this assumption was strongly violated $(\mathrm{P}=0.00005)$. Modeling the differences between municipalities as a random difference in intervention effect across the three municipalities would severely weaken the statistical power of the analysis and the overall estimate would have much less precision than the results from each municipality. Consequently, we have chosen to present results from the three municipalities separately.

The municipalities differed profoundly in some background characteristics of the participating beneficiaries (table 1) as well as in the proportion of sick-listed 
Table 1. Background characteristics of beneficiaries in ordinary sickness benefit management (OSM) and coordinated, tailored, and multidisciplinary (CTM) approach in the study. [SD=standard deviation]

\begin{tabular}{|c|c|c|c|c|c|c|c|c|c|c|c|c|c|c|c|c|c|c|c|c|c|}
\hline & \multicolumn{7}{|c|}{ Municipality 1 (M1) } & \multicolumn{7}{|c|}{ Municipality 2 (M2) } & \multicolumn{7}{|c|}{ Municipality 3 (M3) } \\
\hline & \multicolumn{3}{|c|}{$\begin{array}{c}\text { OSM } \\
(\mathrm{N}=489)\end{array}$} & \multicolumn{3}{|c|}{$\begin{array}{c}\text { CTM } \\
(\mathrm{N}=747)\end{array}$} & \multirow[t]{2}{*}{$\begin{array}{c}\mathrm{P}- \\
\text { value }\end{array}$} & \multicolumn{3}{|c|}{$\begin{array}{c}\text { OSM } \\
(\mathrm{N}=539)\end{array}$} & \multicolumn{3}{|c|}{$\begin{array}{c}\text { CTM } \\
(\mathrm{N}=809)\end{array}$} & \multirow[t]{2}{*}{$\begin{array}{c}\mathrm{P}- \\
\text { value }\end{array}$} & \multicolumn{3}{|c|}{$\begin{array}{c}\text { OSM } \\
(\mathrm{N}=129)\end{array}$} & \multicolumn{3}{|c|}{$\begin{array}{c}\text { CTM } \\
(\mathrm{N}=392)\end{array}$} & \multirow[t]{2}{*}{$\begin{array}{c}\mathrm{P}- \\
\text { value } \\
\end{array}$} \\
\hline & $\%$ & Mean & $\mathrm{SD}$ & $\%$ & Mean & $\mathrm{SD}$ & & $\%$ & Mean & SD & $\%$ & Mean & $\mathrm{SD}$ & & $\%$ & Mean & SD & $\%$ & Mean & SD & \\
\hline Gender & & & & & & & 0.06 & & & & & & & 0.0001 & & & & & & & 0.84 \\
\hline Men & 40.3 & & & 45.7 & & & & 50.5 & & & 39.9 & & & & 37.2 & & & 36.2 & & & \\
\hline Women & 59.7 & & & 54.4 & & & & 49.5 & & & 60.1 & & & & 62.8 & & & 63.8 & & & \\
\hline $\begin{array}{l}\text { Cause of sick- } \\
\text { ness absence }\end{array}$ & & & & & & & 0.35 & & & & & & & 0.67 & & & & & & & 0.41 \\
\hline Mental & 39.0 & & & 41.8 & & & & 46.5 & & & 47.7 & & & & 62.1 & & & 66.1 & & & \\
\hline Somatic & 61.0 & & & 58.2 & & & & 53.5 & & & 52.3 & & & & 37.9 & & & 33.9 & & & \\
\hline Education level & & & & & & & 0.66 & & & & & & & 0.29 & & & & & & & 0.13 \\
\hline Basic & 34.9 & & & 32.3 & & & & 32.9 & & & 31.1 & & & & 25.0 & & & 22.9 & & & \\
\hline Middle & 47.3 & & & 49.0 & & & & 47.1 & & & 45.2 & & & & 59.4 & & & 53.1 & & & \\
\hline Higher & 17.9 & & & 18.7 & & & & 20.0 & & & 23.7 & & & & 15.6 & & & 24.0 & & & \\
\hline Age & & 41.9 & 11.5 & & 41.2 & 11.4 & 0.27 & & 43.0 & 10.7 & & 42.8 & 10.5 & 0.80 & & 39.7 & 11.5 & & 41.0 & 10.8 & 0.22 \\
\hline $\begin{array}{l}\text { Employment } \\
\text { status at sick } \\
\text { listing }\end{array}$ & & & & & & & 0.21 & & & & & & & 0.38 & & & & & & & 0.11 \\
\hline Unemployed & 23.5 & & & 20.5 & & & & 49.5 & & & 47.1 & & & & 27.9 & & & 20.9 & & & \\
\hline Employed & 76.5 & & & 79.5 & & & & 50.5 & & & 52.9 & & & & 72.1 & & & 79.1 & & & \\
\hline $\begin{array}{l}\text { History of long- } \\
\text { term sickness } \\
\text { absence }\end{array}$ & & & & & & & 0.15 & & & & & & & 0.92 & & & & & & & 0.68 \\
\hline Yes & 23.5 & & & 27.2 & & & & 39.3 & & & 39.1 & & & & 34.1 & & & 32.1 & & & \\
\hline No & 76.5 & & & 72.8 & & & & 60.7 & & & 60.9 & & & & 65.9 & & & 67.9 & & & \\
\hline $\begin{array}{l}\text { History of } \\
\text { unemployment }\end{array}$ & & & & & & & 0.81 & & & & & & & 0.13 & & & & & & & 0.37 \\
\hline Yes & 32.9 & & & 32.3 & & & & 53.2 & & & 57.5 & & & & 34.1 & & & 29.8 & & & \\
\hline No & 64.6 & & & 67.7 & & & & 46.8 & & & 42.5 & & & & 65.9 & & & 70.2 & & & \\
\hline $\begin{array}{l}\text { Contacts } \\
\text { with general } \\
\text { practitioner }\end{array}$ & & & & & & & 0.06 & & & & & & & 0.41 & & & & & & & 0.72 \\
\hline $0-6$ & 35.4 & & & 40.7 & & & & 38.0 & & & 35.8 & & & & 27.9 & & & 26.3 & & & \\
\hline$\geq 7$ & 64.6 & & & 59.3 & & & & 62.0 & & & 64.2 & & & & 72.1 & & & 73.7 & & & \\
\hline $\begin{array}{l}\text { History of hos- } \\
\text { pital admission }\end{array}$ & & & & & & & 0.76 & & & & & & & 0.45 & & & & & & & 0.24 \\
\hline No & 41.3 & & & 40.4 & & & & 45.6 & & & 47.7 & & & & 48.1 & & & 42.1 & & & \\
\hline Yes & 58.7 & & & 59.6 & & & & 54.4 & & & 52.3 & & & & 51.9 & & & 57.9 & & & \\
\hline $\begin{array}{l}\text { Purchase of } \\
\text { prescribed } \\
\text { medicine }\end{array}$ & & & & & & & 0.64 & & & & & & & 0.47 & & & & & & & 0.21 \\
\hline No & 65.0 & & & 63.7 & & & & 57.3 & & & 59.3 & & & & 65.1 & & & 58.9 & & & \\
\hline Yes & 35.0 & & & 36.3 & & & & 42.7 & & & 40.7 & & & & 34.9 & & & 41.1 & & & \\
\hline
\end{tabular}

beneficiaries in category 2 and beneficiaries randomized before eight weeks of sickness absence. These differences, which may originate partly from sociodemographical differences between the municipalities and partly from differences between the municipalities in the interpretation and management of the existing legislation, may have had an impact on the effect of the CTM intervention. The fraction of beneficiaries unemployed at the time of inclusion was markedly higher in M2 than M1 and M3 as was the share of beneficiaries with a history of long-term sickness absence. Hence, the beneficiaries in M2 may be more complex cases than those in M1 and M3. In support of this, the recovery rate in OSM was lower in M2 than M1 and M3. Thus, it may be speculated that the CTM intervention with its multidisciplinary team of experts is especially effective in the more complex cases.

In the present study, the CTM intervention builds on a rather complex concept. Complex interventions, which include several interacting active ingredients, are particularly prone to reinvention and implementation failure (17-19), and the large differences in intervention effect between the three municipalities may therefore not be surprising. In agreement with the present study, it has been previously shown that RTW for sick-listed beneficiaries from six different Danish municipalities varied substantially - even after controlling for diagnosis, income, education, and age (20). The authors suggested 
Table 2. Effect of coordinated, tailored and multidisciplinary (CTM) intervention compared with ordinary sickness benefit management (OSM). [HR=hazard ratios; $95 \% \mathrm{Cl}=95 \%$ confidence interval.]

\begin{tabular}{|c|c|c|c|c|}
\hline & $H R$ & $95 \% \mathrm{Cl}$ a & $\begin{array}{l}\text { Recovery } \\
\text { rate }{ }^{\text {b }} \text { CTM } \\
\text { (Poisson) }\end{array}$ & $\begin{array}{l}\text { Recovery } \\
\text { rate b }{ }^{\text {OSM }} \\
\text { (Poisson) }\end{array}$ \\
\hline \multicolumn{5}{|l|}{ Municipality 1 (M1) } \\
\hline Unadjusted & & & 0.0270 & 0.0242 \\
\hline Adjusted c & & & & \\
\hline Restricted exclusion ${ }^{d}$ & & & & \\
\hline \multicolumn{5}{|l|}{ Municipality 2 (M2) } \\
\hline Unadjusted & 1.51 & $1.31-1.74$ & 0.0301 & 0.0199 \\
\hline Adjusted & 1.5 & $1.33-1.78$ & & \\
\hline Restricted exclusion ${ }^{d}$ & 1.50 & $1.32-1.71$ & & \\
\hline \multicolumn{5}{|l|}{ Municipality 3 (M3) } \\
\hline Unadjusted & 0.80 & $0.63-1.03$ & 0.0227 & 0.0281 \\
\hline Adjusted c & 0.84 & $0.65-1.08$ & & \\
\hline Restricted exclusion ${ }^{d}$ & 0.85 & $0.70-1.02$ & & \\
\hline \multicolumn{5}{|c|}{$\begin{array}{l}\text { a Based on Cox proportional hazard model ( } \mathrm{N}=3105) \text {. } \\
\text { b Recovery rates are approximately equal to the probability of recovery } \\
\text { within a week. } \\
\text { c Adjusted for cause of sickness absence, gender, age, educational level, } \\
\text { history of long-term sickness absence, employment status at inclusion } \\
\text { in the study, contact with own practitioner, hospital admission, and pur- } \\
\text { chase of prescribed medicine ( } \mathrm{N}=3105) \text {. } \\
\text { d Robustness analysis with restricted exclusion criteria ( } \mathrm{N}=4189) \text {. }\end{array}$} \\
\hline
\end{tabular}

that these differences might be attributed to variations in the sickness absence management or the skills and attitudes of the social insurance officers. As previously described, the Danish RTW program included a comprehensive and detailed process evaluation to pinpoint the qualitative differences between municipalities with respect to organization, implementation, and management of the intervention (15). The results of the process evaluation will be published later.

In the Danish program, the first three months are defined as an introductory period during which the RTW coordinators and teams become familiar with the interdisciplinary collaboration and the specific tools and methods of the intervention. Thereafter, the RTW coordinators and teams are anticipated gradually to pick up more experience and become more successful during the following months. Analyses of potential timedependency of the effects were performed to shed light on the possible learning processes in the three different municipalities. In M1 and M2, the estimated effect in the first time interval (ie, 1 July 2010-2 January 2011) was smaller than in the three subsequent time intervals (table 3 ), although differences in effects between intervals approached statistical significance only in M2.

In M1, but not in M2 or M3, the effect of the RTWintervention was significantly dependent on the duration of sickness absence since first day of sick listing [ie, the intervention was more effective late in the long-lasting sickness absence spells (table 4)]. In M1, the fraction of beneficiaries in category 2 (ie, unlikely to return to work within three months, but able to participate in RTW activities) was nearly twice as high as in M2 and M3, and it may be speculated that the cases in M1 on average were less complicated than the cases in M2. As indicated earlier in this discussion, the positive effect of the CTM intervention may be particularly apparent in the more complex cases. If so, this may at least partly explain the differences between the effect of the intervention in M1, which presumably had a higher fraction of straightforward cases, and M2. The simple cases may be handled with the same effectiveness in the CTM and OSM, hence leading to no effect of the intervention in the early stages of the absence spells in M1. However, at later stages of the absence spells, when only more complex cases are under consideration (under the assumption that the most straightforward cases have been solved and closed), the effect of the CTM intervention might become superior to OSM, leading to a statistically significant HR for spells that lasted $>42$ weeks in M1. It has been recently demonstrated that timing is crucial for the cost-effectiveness of structured and complex interventions for workers on sick leave due to low-back pain (21). Using theoretical modeling, the authors estimated the optimal time window to be between 8-12 weeks for a population with a slow RTW (RTW of $43 \%$ after 2 weeks and $79 \%$ after 12 weeks). This timeframe is very similar to the timing used in the present study (most participants were included at between 8-10 weeks of sickness absence benefits). However, it should be recognized that the RTW recovery rate in the present study was far lower than the recovery rate characterized as slow in the study on RTW and lowback pain (21).

\section{Strengths and limitations of the study}

The main strengths of this study are the RCT design, the multisite approach, and the large sample size. We used data from a national register to obtain information on recovery from long-term sickness absence, which eliminated recall bias. In designing the study, a low risk of intervention spillover between the CTM and OSM in the RCT was considered to be strength. However, intervention spillover cannot completely be ruled out, and, if this has occurred, the analysis underestimates the effect of the intervention.

In theory, the RCT design eliminates the need to adjust for possible confounders. However, in M2, which had a significant positive intervention effect, the fraction of women receiving CTM was significantly higher than those receiving OSM. Adjustment for a series of possible confounders altered the estimated HR only marginally. Consequently, the gender difference between groups in M2 had no practical importance, and the estimated HR appear as rather robust. Further, a robustness analysis, in which exclusion was very restricted, also yielded similar HR. 
Table 3. Effect of CTM (coordinated, tailored and multidisciplinary) intervention in four time intervals after initiation of the project. [HR=hazard ratios; $95 \% \mathrm{Cl}=95 \%$ confidence interval]

\begin{tabular}{|c|c|c|c|c|c|c|c|c|c|}
\hline & \multicolumn{2}{|c|}{ Interval I } & \multicolumn{2}{|c|}{ Interval II } & \multicolumn{2}{|c|}{ Interval III } & \multicolumn{2}{|c|}{ Interval IV } & \multirow[t]{2}{*}{ P-value } \\
\hline & $\mathrm{HR}$ & $95 \% \mathrm{Cl}^{\mathrm{b}}$ & $\mathrm{HR}$ & $95 \% \mathrm{Cl}^{\mathrm{b}}$ & $\mathrm{HR}$ & $95 \% \mathrm{Cl}^{\mathrm{b}}$ & $\mathrm{HR}$ & $95 \% \mathrm{Cl}^{\mathrm{b}}$ & \\
\hline Municipality 1 (M1) & 1.02 & $0.67-1.54$ & 1.12 & $0.90-1.40$ & 1.23 & $0.94-1.61$ & 1.10 & $0.77-1.58$ & 0.88 \\
\hline Municipality 2 (M2) & 0.91 & $0.60-1.38$ & 1.61 & $1.26-2.07$ & 1.74 & $1.35-2.23$ & 1.45 & $1.04-2.03$ & 0.07 \\
\hline Municipality 3 (M3) & 0.84 & $0.50-1.42$ & 0.85 & $0.57-1.28$ & 0.66 & $0.41-1.08$ & 0.88 & $0.27-2.84$ & 0.87 \\
\hline
\end{tabular}

a Test for equal effects in the four time intervals.

${ }^{\mathrm{b}}$ Based on Cox proportional hazard model.

Table 4. Effect of CTM-intervention in four intervals of time after first day of reporting sick. [HR=hazard ratios; $95 \% \mathrm{Cl}=95 \% \mathrm{con}$ fidence interval]

\begin{tabular}{|c|c|c|c|c|c|c|c|c|c|}
\hline & \multicolumn{2}{|c|}{ Before week 17} & \multicolumn{2}{|c|}{ Week 17-29 } & \multicolumn{2}{|c|}{ Week 30-42 } & \multicolumn{2}{|c|}{ Week 43-55 } & \multirow[t]{2}{*}{ P-value a } \\
\hline & $\mathrm{HR}$ & $95 \% \mathrm{Cl}^{\mathrm{b}}$ & $\mathrm{HR}$ & $95 \% \mathrm{Cl}^{\mathrm{b}}$ & $\mathrm{HR}$ & $95 \% \mathrm{Cl}^{\mathrm{b}}$ & $\mathrm{HR}$ & $95 \% \mathrm{Cl}^{\mathrm{b}}$ & \\
\hline Municipality 1 (M1) & 1.14 & $0.89-1.45$ & 0.87 & $0.69-1.10$ & 1.30 & $0.91-1.86$ & 1.81 & $1.19-2.77$ & 0.02 \\
\hline Municipality 2 (M2) & 1.30 & $0.95-1.78$ & 1.61 & $1.30-1.99$ & 1.54 & $1.13-2.10$ & 1.45 & $0.92-2.28$ & 0.74 \\
\hline Municipality 3 (M3) & 0.89 & $0.59-1.34$ & 0.88 & $0.56-1.24$ & 0.71 & $0.40-1.27$ & 0.62 & $0.29-1.34$ & 0.84 \\
\hline
\end{tabular}

a Test for equal effects in the four time intervals.

${ }^{\circ}$ Based on Cox proportional hazard model.

The Danish RTW program was performed during a period of global economic crises with increasing rates of unemployment throughout Europe. In contrast to many other European countries, it is fairly easy to dismiss employees in Denmark (22). Among the sick-listed beneficiaries included in the RTW program, the unemployment rate increased rapidly from $27 \%$ at the date of sick-listing to $45 \%$ after the third month of sickness absence. Theoretically, it is possible that sick-listed beneficiaries who became unemployed were less motivated to participate in RTW activities than would be the case during a period of economic growth with higher labor demands and better employment possibilities. However, this may be a minor problem since the strongest positive effect of the intervention was obtained in M2 which also had the highest rate of unemployment among the sick-listed beneficiaries.

\section{Impact of results}

The present article demonstrates that a positive effect of the intervention with respect to increasing the recovery rate from long-term sickness absence was obtained in one of three municipalities in the RCT study. However, remarkably large differences in the effect of the CTM intervention were found between municipalities, indicating that contextual factors are of major importance for success or failure of this complex intervention.

\section{Acknowledgments}

The Danish Prevention Fund has granted $€ 32$ million ( 240 million DKK) to finance the cost of the implementation of the Danish RTW program in the 21 participating municipalities. In addition, the Danish Ministry of Employment has granted NRCWE $€ 4.3$ million (32.5 million DKK) to develop, plan, administe, coordinate, and evaluate the program.

Trial registration: ISRCTN43004323

\section{Ethical considerations}

The Danish Data Protection Agency (www.datatilsynet. $\mathrm{dk} /$ ) has been notified of and registered this study. According to the Danish Law, approval from the Danish National Committee on Biomedical Research Ethics (www.cvk.sum.dk) is only mandatory for projects using biological material.

\section{References}

1. Analyse af sygefraværet [Analysis of sickness absence]. Copenhagen: Beskæftigelsesministeriet [Ministry of Employment]; 2008.

2. OECD. Sickness, Disability and work. Breaking the barriers. A synthesis across OECD countries. Paris: OECD; 2010.

3. Schultz IZ, Stowell AW, Feuerstein M, Gatchel RJ. Models of return to work for musculoskeletal disorders. J Occup Rehabil. 
2007;17:327-52. http://dx.doi.org/10.1007/s10926-0079071-6.

4. Briand C, Durand MJ, St-Arnaud L, Corbiere M. Work and mental health: Learning from return-to-work rehabilitation programs designed for workers with musculoskeletal disorders. Int J Law and Psychiatry. 2007;30:444-57. http:// dx.doi.org/10.1016/j.ijlp.2007.06.014.

5. Palmer KT, Harris EC, Linaker C, Barker M, Lawrence W, Cooper C, et al. Effectiveness of community- and workplace-based interventions to manage musculoskeletalrelated sickness absence and job loss. A systematic review. Rheumatology. 2012;51(2):230-42. http://dx.doi. org/10.1093/rheumatology/ker086.

6. Loisel P, Durand MJ, Berthelette D, Vezina N, Baril R, Gagnon D, et al. Disability prevention - New paradigm for the management of occupational back pain. Disease Management \& Health Outcomes. 2001;9:351-60. http:// dx.doi.org/10.2165/00115677-200109070-00001 .

7. Waddell G. The Back Pain Revolution. Edinburgh: Churchill Livingstone; 2004.

8. Bültmann U, Sherson D, Olsen J, Hansen CL, Lund T, Kilsgaard J. Coordinated and tailored work rehabilitation: a randomized controlled trial with economic evaluation undertaken with workers on sick leave due to musculoskeletal disorders. J Occup Rehabil. 2009;19:81-93. http://dx.doi. org/10.1007/s10926-009-9162-7.

9. Ektor-Andersen J, Ingvarsson I, Kullendorff M, Ørbæk P. High cost-benefit of early team-based biomedical and cognitivebehaviour psychological intervention for long-term painrelated sickness absence. J Rehab Med. 2008;40:1-8. http:// dx.doi.org/10.2340/16501977-0127.

10. Mortensen OS, Andersen JH, Ektor-Andersen J, Eriksen HR, Fallentin N, Frost P, et al. Hvidbog om sygefravær og tilbagevenden til arbejdet ved muskel-og skeletbesvær. Årsager og handlemuligheder [White paper on sickness absence and return to work regarding musculosceletal problems. Causes and possibilities for actions]. Copenhagen: National Research Center for the Working Environment Copenhagen; 2008.

11. Borg V, Nexø MA, Kolte IV, Andersen MF. Hvidbog om mentalt helbred, sygefravær og tilbagevenden til arbejde. [White paper on mental health, sickness absence and return to work]. Copenhagen: National Research Center for the Working Environment; 2010.

12. Nielsen MBD, Madsen IEH, Bültmann U, Christensen U, Diderichsen F, Rugulies R. Predictors of return to work in employees sick-listed with mental health problems: findings from a longitudinal study. European J Public Health. 2010;21:806-11. http://dx.doi.org/10.1093/eurpub/ckq171.

13. Franche RL, Cullen K, Clarke J, Irvin E, Sinclair S, Frank J. Workplace-based return-to-work interventions: a systematic review of the quantitative literature. J Occup Rehabil. 2005;15:607-31. http://dx.doi.org/10.1007/s10926-0058038-8.

14. Shaw W, Hong QN, Pransky G, Loisel P. A literature review describing the role of return-to-work coordinators in trial programs and interventions designed to prevent workplace disability. J Occup Rehabil. 2008;18(1):2-15. http://dx.doi. org/10.1007/s10926-007-9115-y.

15. Aust B, Helverskov T, Nielsen MBD, Bjorner JB, Rugulies R, Nielsen K, et al. The Danish national return-to-work program aims, content, and design of the process and effect evaluation. Scand J Work Environ Health. 2012;38:120-33. http://dx.doi. org/10.5271/sjweh.3272.

16. Christensen KB, Lund T, Labiola M, et al. The impact of health behavior on long term sickness absence: Results from DWECS/DREAM. Ind Health. 2007;45:348-51. http://dx.doi. org/10.2486/indhealth.45.348.

17. Oakley A, Strange V, Bonell C, Allen E, Stephenson J, RIPPLE study team. Process evaluation in randomized controlled trials of complex interventions. BMJ. 2006;332:413-6. http:// dx.doi.org/10.1136/bmj.332.7538.413.

18. Craig P, Dieppe P, Macintyre S, Michie S, Nazareth I, Petticrew M. Developing and evaluating complex interventions: the new Medical Research Council guidance. BMJ. 2008 Sep 29;337:a1655.

19. Nielsen K, Randall R. Opening the black box: Presenting a model for evaluating organizational-level interventions. Eur J Work Org Psych. July 2012: online first. http://dx.doi.org/10. 1080/1359432X.2012.690556

20. Stoltenberg CD, Skov PG. Determinants of return to work after long-term sickness absence in six Danish municipalities. Scand J Public Health. 2010;38(3):299-308. http://dx.doi. org/10.1177/1403494809357095.

21. van Duijn M, Eijkemans MJ, Koes BW, Koopmanschap MA, Burton KA, Burdorf A.The effects of timing on the costeffectiveness of interventions for workers on sick leave due to low back pain. Occup Environ Med. 2010 Nov;67(11):744-50. http://dx.doi.org/10.1136/oem.2009.049874.

22. Flexicurity and welfare reform: a review. Viebrock E, Clasen J. Socioecon Rev. 2009;7(2):305-31.

Received for publication: 11 April 2013 